\title{
A Comparative Assessment of Effects of Major Mediators of Acute Phase Response (IL-1, TNF- $\alpha$, IL-6) on Breathing Pattern and Survival Rate in Rats with Acute Progressive Hypoxia
}

\author{
Zh. A. Donina ${ }^{a, *}$, E. V. Baranova ${ }^{a}$, and N. P. Aleksandrova ${ }^{a}$ \\ ${ }^{a}$ Pavlov Institute of Physiology, Russian Academy of Sciences, St. Petersburg, Russia \\ *e-mail: zdonina@mail.ru
}

Received April 27, 2021

Revised May 27, 2021

Accepted June 6, 2021

\begin{abstract}
A pressing issue of the day is the identification of therapeutic targets to suppress the "cytokine storm" in COVID-19 complicated by acute respiratory distress syndrome (ARDS) with concomitant hypoxemia. However, the key cytokine and its relative contribution to the pathogenesis of ARDS, which leads to high mortality, are unknown. A comparative assessment of the effect of elevated systemic levels of pro-inflammatory cytokines IL-1 $1 \beta$, TNF- $1 \alpha$ and IL- 6 on the respiratory patterns and survival rate in rats was carried out under progressively increasing acute hypoxia. Increasing hypoxia was simulated by a rebreathing method (from normoxia to apnea). The recorded parameters were the breathing pattern components (tidal volume and respiratory rate), minute ventilation (MV), oxygen saturation, apnea onset time, and posthypoxic survival rate. A comparative analysis was carried out under mild, moderate and severe hypoxia $\left(\right.$ at $\mathrm{F}_{\mathrm{I}} \mathrm{O}_{2}=15,12$ and $8 \%$, respectively). It was shown that increasing hypoxia was accompanied by an acute suppression of the compensatory elevation of MV in rats with increased systemic levels of IL- $1 \beta$ and TNF-1 $\alpha$. By contrast, IL-6 caused an intensive elevation of MV with increasing hypoxia. Acute hypoxia $\left(\mathrm{F}_{\mathrm{I}} \mathrm{O}_{2}<8 \%\right)$, in all experimental series, was accompanied by an impairment of the respiratory rhythm up to the development of apnea. Posthypoxic breathing restoration (survival rate) was $50 \%$ with IL- $1 \beta$ and TNF- $1 \alpha$ and only $10 \%$ with IL- 6 . The obtained results indicate that the elevated IL-6 level, despite the absence of respiratory disorders at the initial stage of the developing pathologic process, leads to a higher mortality in rats compared to IL- $1 \beta$ and TNF- $1 \alpha$. This allows considering IL-6 as an early prognostic biomarker of a high risk of mortality under severe hypoxemia.
\end{abstract}

DOI: $10.1134 / \mathrm{S} 0022093021040177$

Keywords: cytokine storm, acute respiratory distress syndrome, increasing hypoxemia, apnea

The universal nonspecific response of the organism to the impact of damaging exo- and endogenous factors caused by the invasion of a viral or bacterial infection is a systemic inflammatory response [1]. The development of a systemic inflammatory response relies on the uncontrolled massive production of acute-phase response mediators, including such pro-inflammatory cytokines 
as interleukin-1 $\beta$ (IL-1 $\beta$ ), interleukin-6 (IL-6), tumor necrosis factor-alpha (TNF- $\alpha$ ), and many other biologically active substances [2]. In turn, the production of a large amount of pro-inflammatory mediators leads to the activation of immune cells, which release new quanta of mediators due to the presence of an uncontrolled positive feedback between these processes [3]. A vicious circle thus arises, causing tissue destruction in the focus of inflammation, the spread of the response to neighboring tissues, and the release of pro-inflammatory cytokines into the bloodstream. As a result, inflammation becomes systemic, generalized, covering the whole organism.

Currently, it has been proven that the massive cytokine-releasing cascade, called "cytokine storm", is associated with multiple organ failure [4, 5], with the lungs being, in most cases, a target organ [6]. Hyperactivation of the immune response can cause the development of acute respiratory distress syndrome (ARDS) characterized by pneumonia, exudative lesions, decreased elastic properties of the lungs, pulmonary embolism, inadequate relationship between ventilation and perfusion of pulmonary alveoli, and impaired gas exchange, which ultimately threatens respiratory arrest and lethal outcome [7 ]. There is evidence that the severity of the clinical course of the disease and inhospital mortality of patients are aggravated by the main manifestation of ARDS, a rapidly increasing hypoxemia [8, 9], which causes the additional expression of circulatory pro-inflammatory cytokines, such as TNF- $\alpha$, IL-1 $\beta$ and IL-6 [10]. Clinical observations have found a close link between the degree and duration of hypoxemia and mortality in patients with ARDS [11].

There is also evidence that, among the numerous cytokines released during the systemic inflammatory response, one of the main mediators of viral pneumonia is IL- $1 \beta$, which is used as a biomarker to classify the severity of the disease [7]. IL-1 $\beta$ is the most studied pleiotropic cytokine whose effects are similar to those of TNF- $\alpha$, also referring to the main pro-inflammatory cytokines, which in turn promotes the production of other cytokines, including IL-6 [12]. This cytokine, having both pro-inflammatory and anti-inflammatory properties, is expressed by stromal and immune cells, while its release is regulated, spe- cifically, by IL-1 $\beta$ and TNF- $\alpha$ [13]. In addition, any inflammatory stimulus increases the expression of IL-6, which can also serve as a trigger for IL-1 $\beta$ and TNF- $\alpha$. Large-scale clinical studies conducted on hospitalized patients diagnosed with COVID-19 found that, in contrast to the mild form, the severe and critical course of the disease is characterized by a high IL-6 expression, which correlates with respiratory failure, secondary infections, and mortality. Elevated IL-6 levels were also associated with the risk of death in patients with ARDS without COVID-19 [6, 14].

Currently, in the context of the coronavirus disease (COVID-19) pandemic, novel approaches to the therapy of systemic inflammation are being intensively developed, such as inhibition of the production and activity of pro-inflammatory cytokines, stimulation of the synthesis of antiinflammatory cytokines, and searching for therapeutic targets to suppress the cytokine storm. In addition, given the high rate of in-hospital mortality, there is a need to identify early predictive biomarkers to stratify hospitalized patients in accordance with the probability of mortality risk.

An important criterion for the diagnosis, deciphering the pathogenesis, determining the prognosis and therapeutic tactics of treatment is the set of individual components of the respiratory cycle-depth, respiratory rate, minute lung ventilation, etc. (breathing pattern), which changes with the onset and progression of respiratory diseases. However, the relative contribution of IL-1 $\beta$, IL- 6 , and TNF- $\alpha$ to changes in the breathing pattern against the background of progressive hypoxemia has hardly been studied.

In connection with the aforesaid, this work aimed to compare the effect of the key proinflammatory cytokines IL-1 $\beta$, IL- 6 , and TNF- $\alpha$ on the breathing pattern, blood oxygenation, and the rate of mortality during increasing hypoxia.

\section{MATERIALS AND METHODS}

The work was carried out on animals from the Pavlov Institute of Physiology's Collection of Laboratory Mammals of Varied Taxonomic Affiliation supported by the Russia's Bioresource Collections program. All experimental procedures that involved animals complied with the ethical 
standards approved by legal acts of the Russian Federation: Order of the Ministry of Health of the Russian Federation of 01.04.2016 No. 199n "On the approval of the Good Laboratory Practice Regulations" (Registered in the Ministry of Justice of the Russian Federation on 15.08.2016 No. 43232), as well as with the Basel Declaration and recommendations of the Bioethics Committee at the Pavlov Institute of Physiology, Russian Academy of Sciences.

A study was carried out in acute experiments on 58 Wistar rats weighing 280-300 g, and anesthetized with urethane $(1000 \mathrm{mg} / \mathrm{kg}$, i.p.). The depth of anesthesia was monitored by the degree of the corneal reflex manifestation. Rats were divided into 5 groups: group 1-intact animals (vivarium control), group 2-control animals administered with $1 \mathrm{~mL}$ of saline $(0.9 \% \mathrm{NaCl})$, group 3 -animals administered with interleukin-1 $\beta$ (recombinant human IL-1 $\beta$, State Institute of Highly Pure Biopreparations, Russia; $500 \mathrm{ng} / \mathrm{mL}$ of saline), group 4-animals administered with tumor necrosis factor- $\alpha$ (TNF- $\alpha$, Sigma, USA; $40 \mathrm{mg} / \mathrm{kg}$ ), group 5 - animals administered with interleukin-6 (IL-6, Sigma, USA; $50 \mu \mathrm{g} / \mathrm{kg}$ ).

After recording the baseline (normoxic) values, the agents under study were injected into the femoral vein, and after $70 \mathrm{~min}$, the rats were switched to breathing with a hypoxic mixture with a progressive decline of the oxygen content (from normoxia to a complete respiratory arrest) using the rebreathing method [15]. The onset time and duration of hypoxic apnea, as well as the fraction of inspired oxygen in the gas mixture $\left(\mathrm{F}_{\mathrm{I}} \mathrm{O}_{2}\right)$, and posthypoxic survival rate (lethality) (\%) vs. the control group were recorded. The respiratory arrest for 1 min was equated to death of the animals. During the experiment, the studied parameters were recorded continuously at every minute, and a comparative assessment was carried out at $\mathrm{F}_{\mathrm{I}} \mathrm{O}_{2}=15,12$ and $8 \%$.

The main parameters of external respiration, such as the volume velocity of the inspiratory flow (Vi), tidal volume $\left(\mathrm{V}_{\mathrm{T}}\right)$, and respiratory rate (RR), were recorded by the pneumotachographic method. The minute ventilation (MV) was calculated as a product of $\mathrm{V}_{\mathrm{T}}$ and $\mathrm{RR}$. To measure esophageal (a surrogate of intrathoracic or pleural) pressure $\left(\mathrm{P}_{\mathrm{es}}\right)$, the balloonographic method was used. Blood oxygenation $\left(\mathrm{SpO}_{2}, \%\right)$ was determined using the UT100 veterinary pulse oximeter (Zoomed, Russia). $\mathrm{F}_{\mathrm{I}} \mathrm{O}_{2}$ in the inspired gas mixture was measured by the PGK-06 oxygen analyzer (Insovt, Russia), and the fraction of carbon dioxide in the inspired gas mixture $\left(\mathrm{F}_{\mathrm{iCO} 2}\right)$ was measured with the MAG-6P multicomponent gas analyzer (Exis, Moscow). After the experiment, animals were euthanized by an overdose of urethane.

The pneumotachogram and $\mathrm{P}_{\mathrm{es}}$ pressure signals were digitized and stored on a PC HDD using a hardware-software complex created on the basis of the Biograf-7 biological data collection device (St. Petersburg State University of Aerospace Instrumentation, Russia).

Statistical data analysis was carried out using Statistica 10.0 (Windows) and Microsoft Office Excel 2020 software packages. To check the sample for normal distribution, the KolmogorovSmirnov test was used; the resulting significance level $(p \geq 0.2)$ indicated that the grouped data samples followed a normal distribution. Then, the values before and after drug the injection of the above agents were assessed using the paired Student's $t$-test and two-way (ANOVA) for the hypoxia-normoxia and control-agent factors. Differences were considered significant at $p<$ 0.05 ; the data in the figures and table are presented as $M \pm S E$.

\section{RESULTS}

As follows from Table 1, under normoxic conditions, significant changes in all the studied parameters were only observed with an increase in IL-1 $\beta$, while TNF- $\alpha$ caused an increase in $V_{T}$ and $\mathrm{MV}$, and IL-6 did not affect the parameters of external respiration at all.

Under hypoxic exposure, in the control group, under mild $\left(\begin{array}{lll}15 \% & \mathrm{O}_{2}\end{array}\right)$ and moderate $\left(\begin{array}{lll}12 \% & \mathrm{O}_{2}\end{array}\right)$ hypoxia, there was an considerable increment in MV, by $63 \pm 12 \%$ and $60 \pm 10 \%$, respectively $(p<0.05)$, compared to normoxia, while under acute hypoxia $\left(8 \% \mathrm{O}_{2}\right)$, MV increased to a lesser extent, by $36 \pm 7 \%$ (Fig. 1c).

A similar dynamics of MV under hypoxia was also observed in rats after IL-1 $\beta$ and TNF- $\alpha$ administration, with the differences relating to the 
Table 1. Mean values of external respiration parameters and blood oxygenation in rats after NaCl, IL-1 $\beta, \mathrm{TNF}-\alpha$, and IL-6 administration under normoxia

\begin{tabular}{|c|c|c|c|c|c|}
\hline \multirow[b]{2}{*}{ Variables } & \multirow[b]{2}{*}{$\begin{array}{c}\text { Intact } \\
(n=10)\end{array}$} & \multicolumn{4}{|c|}{70 min after administration } \\
\hline & & $\begin{array}{c}\mathrm{NaCl} \\
\text { (control) } \\
(n=12)\end{array}$ & $\begin{array}{c}\text { IL-1 } \beta \\
(n=12)\end{array}$ & $\begin{array}{l}\text { TNF- } \alpha \\
(n=12)\end{array}$ & $\begin{array}{c}\text { IL-6 } \\
(n=12)\end{array}$ \\
\hline Tidal volume, $\mathrm{mL}$ & $0.9 \pm 0.2$ & $1.0 \pm 0.2$ & $2.3 \pm 0.4^{*}$ & $1.4 \pm 0.2^{*}$ & $1.2 \pm 0.1$ \\
\hline Respiratory rate, $\min ^{-1}$ & $80 \pm 5$ & $83 \pm 4$ & $93 \pm 5^{*}$ & $78 \pm 1$ & $79 \pm 0.1$ \\
\hline Minute ventilation, $\mathrm{mL} / \mathrm{min}$ & $90.2 \pm 7.1$ & $92.3 \pm 6.5$ & $214.9 \pm 7.0^{* *}$ & $120.5 \pm 5.4^{*}$ & $95.2 \pm 4.3$ \\
\hline Esophageal pressure, $\mathrm{cm} \mathrm{H}_{2} \mathrm{O}$ & $0.5 \pm 0.1$ & $0.5 \pm 0.1$ & $0.7 \pm 0.2^{*}$ & $0.6 \pm 0.1$ & $0.6 \pm 0.1$ \\
\hline Oxygen saturation, $\%$ & $96 \pm 1$ & $95 \pm 1$ & $88 \pm 3^{*}$ & $95 \pm 2$ & $84 \pm 4^{*}$ \\
\hline
\end{tabular}

Data are expressed as $M \pm S E M .{ }^{*} p<0.05 ;{ }^{* *} p<0.001 v$ s. control $(\mathrm{NaCl})$
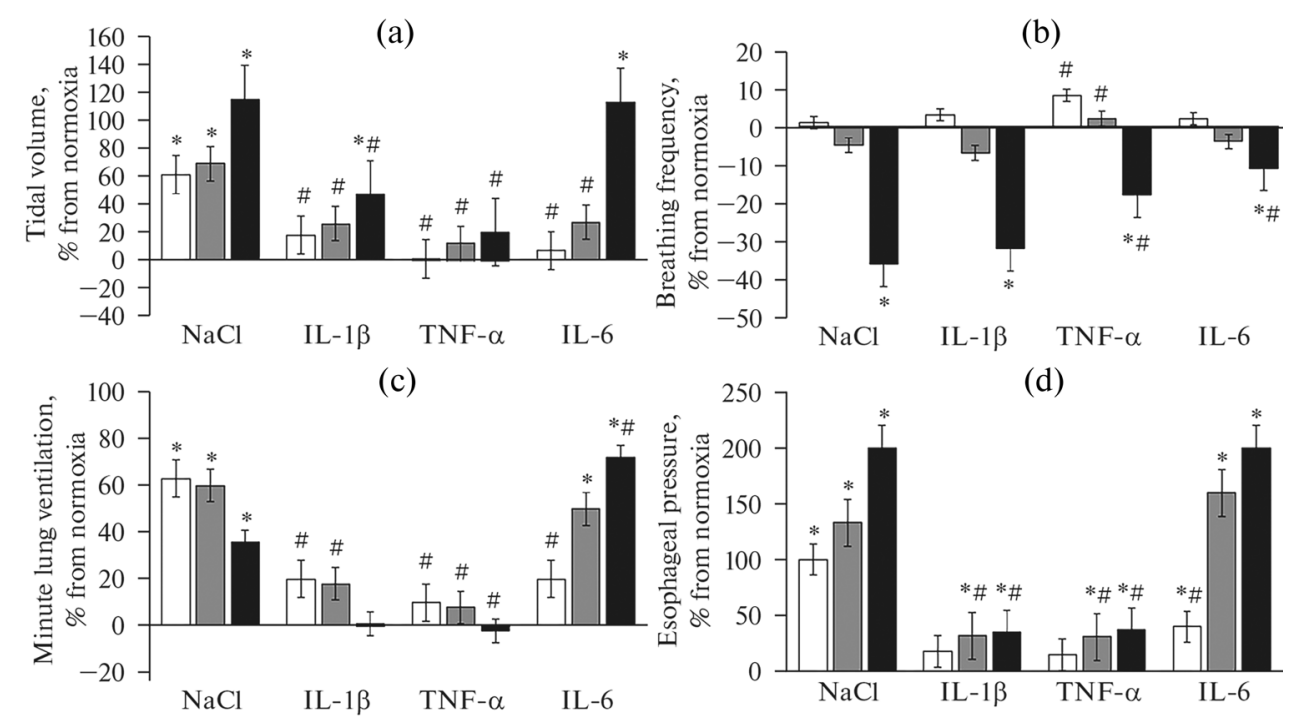

(d)

$\square 15 \% \mathrm{O}_{2} \square 15 \% \mathrm{O}_{2} \square 8 \% \mathrm{O}_{2}$

Fig. 1. Increments in external respiration parameters to increasing hypoxia in rats with elevated IL- $1 \beta$, TNF- $\alpha$ and IL-6 levels. Data are presented as the $M \pm S E M\left(n=12\right.$ in each group) $;{ }^{*} p<0.05$ vs. normoxia, $\# p<0.05 v s$. control ( $\left.\mathrm{NaCl}\right)$. X-axisgroups studied, Y-axis-increments in \% of normoxia: (a) - tidal volume, (b) - respiratory rate, (c) - minute ventilation, (d) esophageal pressure. A sharp weakening of the ventilatory response to increasing hypoxia was observed with an increase in systemic IL- $1 \beta$ and TNF- $\alpha$ levels. IL-6 did not inhibit the ventilatory response to increasing hypoxia, causing only an insignificant decrease in the respiratory rate and not affecting other parameters compared to the control animals.

degree of increment, which was significantly lower than in control rats. For instance, in rats administered with IL-1 $\beta, \mathrm{MV}$ at the level of $15 \% \mathrm{O}_{2}$ increased by $20 \pm 7 \%$, at $12 \% \mathrm{O}_{2}$ by $18 \pm 8 \%$, and at $8 \% \mathrm{O}_{2}$, there was no increment in MV (its value corresponded to those under normoxia) (Fig. 1c). In the group administered with TNF- $\alpha$, at $15 \%$ $\mathrm{O}_{2}$, MV increased by $10 \pm 3 \%$, at $12 \% \mathrm{O}_{2}$ by $18 \pm 4 \%$, respectively $(p>0.05)$; at $8 \% \mathrm{O}_{2}$, there was no increase in MV. A decrease in MV increments under hypoxia in rats with elevated IL-1 $\beta$ and TNF- $\alpha$ levels resulted from decreased incre- ments in inspiratory $P_{\mathrm{es}}$ and $\mathrm{V}_{\mathrm{T}}$ fluctuations (Figs. 1a, 1d). RR under mild and moderate hypoxia changed insignificantly. In both control and experimental groups, a significant decrease in RR was only observed under severe hypoxia $(8 \%$ $\mathrm{O}_{2}$ ) (Fig. 1b).

In rats with an increased systemic IL-6 level, the opposite dynamics of the respiratory parameters was observed. As hypoxia increased, there was a significant increase in the MV increment relative to normoxia. For instance, at $15 \% \mathrm{O}_{2}$, the MV increment was $20 \pm 3 \%(p>0.05)$, at $12 \% \mathrm{O}_{2}$ 




Fig. 2. Effects of different degrees of hypoxia on blood oxygenation in rats with elevated of IL-1 $\beta$, TNF- $\alpha$ and IL-6 levels. Data are presented as $M \pm S E M\left(n=12\right.$ in each group); ${ }^{*} p<0.05$, ${ }^{* *} p<0.001 v s$. intact rats under normoxia. X-axis-groups studied; Y-axis-absolute $\mathrm{SpO}_{2}$ values, dotted line corresponds to initial $\mathrm{SpO}_{2}$ values in control rats under normoxia.

$50 \pm 9 \%$, and at $8 \% \mathrm{O}_{2} 72 \pm 13 \%$, respectively $(p<0.05)$. At the same time, a significant increase in $\mathrm{V}_{\mathrm{T}}$ and $\mathrm{P}_{\mathrm{es}}$ increments was observed, exceeding the corresponding values in the control group under severe hypoxia (Figs. 1a, 1d). RR decreased to a lesser extent than in animals of other groups.

Blood oxygenation $\left(\mathrm{SpO}_{2}\right)$ with increasing hypoxia decreased in all the studied groups compared to the normoxic control (95\%). The most pronounced decrease in $\mathrm{SpO}_{2}$ (up to $46 \%$ ) was observed in rats administered with IL-1 $\beta$ under acute hypoxia, while the dynamics of $\mathrm{SpO}_{2}$ falling with increasing hypoxia was comparable to the control. In rats administered with TNF- $\alpha, \mathrm{SpO}_{2}$ stabilized at the $75 \%$ level, regardless of the degree of an increase in hypoxia (Fig. 2). IL-6 also caused a decrease in $\mathrm{SpO}_{2}$ with increasing hypoxia: under the maximum degree of hypoxia $\left(\mathrm{F}_{\mathrm{I}} \mathrm{O}_{2}=8 \%\right), \mathrm{SpO}_{2}$ was $66 \%$.

Increasing acute hypoxia $\left(\mathrm{F}_{\mathrm{I}} \mathrm{O}_{2}<8 \%\right)$, in all the experimental series, was accompanied by an impairment of rhythmic breathing, turning eventually into apnea. However, it should be noted that respiratory arrest in the studied groups occurred under different degrees of hypoxia: in the control group, apnea was observed at $\mathrm{F}_{\mathrm{I}} \mathrm{O}_{2} 3$ $4 \% \mathrm{O}_{2}$, in the groups administered with IL- $1 \beta$ at $7-8 \%$ O2, with TNF- $\alpha$ at $3-4 \% \mathrm{O}_{2}$, with IL-6 at $6-7 \% \quad \mathrm{O}_{2}$. The posthypoxic restoration of the inspiratory activity (survival rate) in the groups with elevated IL- $1 \beta$ and TNF- $\alpha$ levels decreased 2-fold compared to the control, i.e. respiration was restored only in $50 \%$ of the experimental animals, while in the control group the survival rate was $100 \%$. A highest mortality rate was found in rats administered with IL-6, in which a spontaneous restoration of breathing in the posthypoxic period was observed only in $10 \%$ of cases.

\section{DISCUSSION}

Comparative analysis of respiratory effects of the three key proinflammatory cytokines showed that in rats administered with IL- $1 \beta$ and TNF- $\alpha$, a compensatory increase in $\mathrm{MV}$ decreases in response to hypoxic exposure compared to the control, while IL-6 has an opposite effect, i.e. it does not depress, but, instead, increases the increment in MV as the hypoxic exposure rises. Particularly sharp differences are observed under the effect of a severe degree of hypoxia $\left(8 \% \mathrm{O}_{2}\right)$.

A negative dynamics of MV increments within the individual groups (control, IL-1 $\beta$, TNF- $\alpha$ ) was observed against the background of a positive dynamics of $\mathrm{P}_{\mathrm{es}}$ and $\mathrm{V}_{\mathrm{T}}$, being caused by a significant decrease in RR. The most dramatic decrease in RR was observed under severe hypoxia. At the same time, with a positive dynamics of $\mathrm{P}_{\mathrm{es}}$ and $\mathrm{V}_{\mathrm{T}}$ in the groups with elevated IL- $1 \beta$ and TNF- $\alpha$ systemic levels, an increase in these parameters was significantly lower than in the control group. Under severe hypoxia, against the background of 
IL-6 action, RR decreased to a lesser extent than in the control group, and the $\mathrm{V}_{\mathrm{T}}$ increment corresponded to the control level. As a result, under a combined effect of severe hypoxia and IL-6, MV was higher than in the control and other experimental groups.

To date, it has been established that the cytokines IL- $1 \beta$ and TNF- $\alpha$ are involved in neuroimmune interactions in the brain regions responsible for the central regulation of breathing. This is further supported by the data indicating that IL- $1 \beta$ and TNF- $\alpha$ receptors are found in the solitary tract nucleus and ventrolateral part of the medulla oblongata $[12,16,17]$. It was also found that IL- $1 \beta$ and TNF- $\alpha$ are expressed on sensory cells of the carotid body, reducing the sensitivity of glomus cells to oxygen deficiency [18]. Therefore, IL-1 $\beta$ and TNF- $\alpha$-mediated neuroimmune interactions can also be involved in the peripheral mechanisms of respiratory control that modulate the response to hypoxia and arterial blood saturation with oxygen. As shown in the acute pneumonia model, levels of IL- $1 \beta$ and TNF- $\alpha$, but not IL-6, increase in the bronchoalveolar fluid and lung tissue [19].

In addition, in contrast to IL- $1 \beta$ and TNF- $\alpha$, IL-6 has not only pro-inflammatory, but also antiinflammatory properties [20]. Moreover, IL-6 is classified as a myokine expressed by muscle fibers during exercise [21]. IL-6 was shown to exhibit anti-inflammatory properties during muscle contraction, while an increased IL-6 plasma level additionally causes the expression of more powerful anti-inflammatory cytokines, such as IL-10 and an IL- $1 \beta$ receptor antagonist, and at the same time inhibits the synthesis of the pro-inflammatory cytokine TNF- $\alpha$ [21]. These data can to some extent account for the differences we obtained in the responses of external respiration to increasing hypoxia between the groups with increased IL- $1 \beta$ and TNF- $\alpha$ systemic levels and the group with an elevated IL-6 level.

Our present results indicate that IL-6 affects the respiratory system to a lesser extent than IL-1 $\beta$ and TNF- $\alpha$. It was found that it does not have a direct negative effect on the main inspiratory muscle, diaphragm [22]. Our results are consistent with these data, since under normoxic conditions IL-6 did not cause a decrease in $\mathrm{P}_{\mathrm{es}}$ which reflects the total respiratory muscle effort. Increasing hypoxia, against the background of IL-6 administration, caused enhanced respiratory muscle contractions, an increase in $\mathrm{P}_{\mathrm{es}}$, and a corresponding increase in MV. However, despite the absence of respiratory failure and a significant decrease in $\mathrm{SpO}_{2}$ in this group of rats, the survival rate was only $10 \%$ compared to the control, i.e. 5 times lower than in other experimental groups. The facts we discovered can be explained as follows. It is well known that, to detect hypoxemia in clinical practice, a noninvasive method of pulse oximetry $\left(\mathrm{SpO}_{2}\right)$ is often used, which, however, reflects not a true oxygen tension in arterial blood $\left(\mathrm{PaO}_{2}\right)$, but a hemoglobin saturation with oxygen. According to the physiological principles [23], oxygen release from hemoglobin into the blood depends primarily on the position of the S-shaped oxyhemoglobin dissociation curve. Hypocapnia and respiratory alkalosis that result from hyperventilation shift the dissociation curve leftward and increase the affinity of hemoglobin for oxygen, thus hampering oxygen release into the blood, and this can explain a high $\mathrm{SpO}_{2}$ level at a very low $\mathrm{PaO}_{2}$ [24]. A similar discrepancy between the hypoxemia severity and minor respiratory discomfort, the so-called silent or happy hypoxia, was found in patients with COVID-19 [8], as well as in healthy people staying under high-altitude conditions, when hypocapnia significantly shifts the oxyhemoglobin dissociation curve and increases hemoglobin saturation with oxygen [25]. Based on these facts, it can be assumed that one of the probable causes of high mortality in rats administered with IL-6 may be a severe arterial hypoxemia, despite the retention of $\mathrm{SpO}_{2}$ and the absence of signs of respiratory failure [26]. In rats with elevated IL- $1 \beta$ and TNF- $\alpha$ levels, a significant depression of lung ventilation was observed under increasing hypoxia; in these conditions, hypoventilation is inevitably accompanied by hypercapnia [27]. It is possible that the lack of hypocapnia in these groups contributed to a higher survival rate of the animals.

The revealed differences in the $\mathrm{SpO}_{2}$ level under increasing hypoxia between the studied groups suggest the presence of multiple mechanisms for the tested cytokines to affect the development of hypoxemia. There is evidence that, in 
addition to changing the position of the oxyhemoglobin dissociation curve, cytokines may directly affect the heme group of hemoglobin [28], intrapulmonary shunting [29], ventilation-perfusion ratios and diffusion capacity of the lungs [30], intravascular blood microclotting [31], etc.

In addition, the higher mortality rate of animals administered with IL-6, despite the lack of respiratory decompensation, may have been associated with its negative impact not on the respiratory system, but on the cardiovascular system. It has been shown that microinjection of IL-6 directly into the solitary tract nucleus modulates input (afferent) signals from baroreceptors, being thus involved in the regulation of the cardiovascular system [32].

Thus, IL-1 $\beta$, TNF- $\alpha$ and IL-6, under conditions of progressively increasing hypoxia, have different modulatory effects on the breathing pattern, hemoglobin oxygen saturation, and the survival rate of rats after hypoxic apnea. IL- $1 \beta$ and TNF- $\alpha$ cause acute respiratory failure, which develops already at an early developmental stage of the pathological process due to suppression of a compensatory increase in lung ventilation to an increasing hypoxic stimulus, mediated by a impairment of the central and peripheral regulatory mechanisms of respiration. IL-6, despite the lack of obvious signs of respiratory decompensation, in contrast to IL- $1 \beta$ and TNF- $\alpha$, leads to a greater mortality in rats, probably due to a more rapid increase in arterial hypoxemia. These findings can serve as a basis for assessing the systemic IL-6 level as an early prognostic biomarker of the likelihood (high risk) of death under severe forms of acute respiratory distress syndrome.

\section{AUTHORS' CONTRIBUTION}

Problem specification, experimental design, manuscript writing: Zh.A.D.; data collection and processing: E.A.B.; manuscript editing: N.P.A.

\section{FUNDING}

This work was supported by the Russian federal budget allotted to Pavlov Institute of Physiology (Russian Academy of Sciences) for the implementation of the governmental assignment.

\section{CONFLICT OF INTEREST}

The authors declare that they have neither evident nor potential conflict of interest related to the publication of this article.

\section{REFERENCES}

1. Simbircev AS, Totolyan AA (2015) Cytokines in laboratory diagnosis. Infectious diseases: News Views Education 2: 82-98. (In Russ).

2. Hocker AD, Stokes AJ, Powell FL, Huxtable AG (2017) The impact of inflammation on respiratory plasticity. Exp Neurol 287:243-253. https:// doi.org/10.1016/j.expneurol.2016.07.022

3. Behrens EM, Koretzky GA (2017) Review: Cytokine storm syndrome: Looking toward the precision medicine era. Arthritis \& Rheumatol 69:1135-1143. https://doi.org/10.1002/art.40071

4. Azkur AK, Akdis M, Azkur D, Sokolowska M, Van De Veen W, Bruggen MC, O'Mahony L, Gao Y, Nadeau K, Akdis AC (2020) Immune response to SARS-CoV-2 and mechanisms of immunopathological changes in COVID-19. Allergy 75:15641581. https://doi.org/10.1111/all.14364

5. Sun X, Wang T, Cai D, Hu Z, Chen J, Liao H, Zhi L, Wei H, Zhang Z, Qiu Y, Wang J, Wang A (2020) Cytokine storm intervention in the early stages of COVID-19 pneumonia. Cytokine Growth Factor Rev 53:38-42. https://doi.org/ 10.1016/j.cytogfr.2020.04.002

6. Liu BW, Li M, Zhou ZG, Guan X, Xiang YF (2020) Can we use interleukin-6 (IL-6) blockade for coronavirus disease 2019 (COVID-19)induced cytokine release syndrome (CRS)? J Autoimmun 111:102452. https://doi.org/ 10.1016/j.jaut.2020.102452

7. Huang C, Wang Y, Li X, Ren L, Zhao J, Hu Y, Zhang L, Han G, Xu J, Gu X, Cheng Z, Yu T, Wei Y, Wu W, Xie X, Yin W, Liu M, Xiao Y, Gao H, Guo L, Xie J, Wang G, Jiang R, Gao Z, Jin Q, Wang J, Cao B (2020) Clinical features of patients infected with 2019 novel coronavirus in Wuhan, China. Lancet 395:497-506. https:// doi.org/10.1016/S0140-6736(20)30183-5

8. Dhont S, Eric Derom E, Braeckel EV, Depuydt P, Lambrecht BN (2020) The pathophysiology of 'happy' hypoxemia in COVID-19. Respirat Res 21:198. https://doi.org/10.1186/ s12931-020-01462-5

9. Xie J, Covassin N, Fan Z, Singh P, Gao W, Li G, Kara T, Somers VK (2020) Association between hypoxemia and mortality in patients with 
COVID-19. Mayo Clin Proc 95:1138-1147. https://doi.org/10.1016/j.mayocp.2020.04.006

10. Bein T, Grasso S, Moerer O, Quintel M, Guerin C, Deja M, Brondani M, Mehta S (2016) The standard of care of patients with ARDS: ventilatory settings and rescue therapies for refractory hypoxemia. Intensive Care Med 42:699-711. https://doi.org/10.1007/s00134-016-4325-4

11. Gilbert JA (2018) Advancing towards precision medicine in ARDS. Lancet Respir Med 6:494-495. https://doi.org/10.1016/S2213-2600(18)30156-5

12. Yee-Hsee $\mathrm{H}$, Litvin DG, Abigail RZ, Nethery DE, Thomas ED, Jacono FJ (2020) Brainstem inflammation modulates the ventilatory pattern and its variability after acute lung injury in rodents. J Physiol 598:2791-281. https:// doi.org/10.1113/JP280060

13. Hunter CA, Jones SA (2015) IL-6 as a keystone cytokine in health and disease. Nat Immunol 16:448-457. https://doi.org/10.1038/ni.3153

14. Somers EC, Eschenauer GA, Troost JP, Golob JL, Gandhi TN, Wang L, Zhou N, Petty LA, Baang JH, Dillman NO, Frame D, Gregg KS, Kaul DR, Nagel J, Patel TS, Zhou S, Lauring AS, Hanauer DA, Martin E, Sharma P, Fung CM, Pogue JM (2020) Tocilizumab for treatment of mechanically ventilated patients with COVID-19. Clin Infect Dis 2020 ciaa954. https:// doi.org/10.1093/cid/ciaa954

15. Donina ZhA, Baranova EV, Alexandrova NP (2019) Inhibition of the hyperproduction of nitric oxide during progressively increasing hypoxia under the action of IL- $1 \beta$ reduces the survival of rats after acute hypoxia. Russ J Physiol 105: 15141525. (In Russ). https://doi.org/10.1134/ S0869813919120033

16. Probert L (2015) TNF and its receptors in the CNS: The essential, the desirable and the deleterious effects. Neuroscience 302:2-22. https:// doi.org/10.1016/j.neuroscience.2015.06.038

17. Baig AM, Khaleeq A, Ali U, Syeda H (2020) Evidence of the COVID-19 Virus Targeting the CNS: Tissue Distribution, Host-Virus Interaction, and Proposed Neurotropic Mechanisms. ACS Chem Neuroscie 11:995-998. https://doi.org/10.1021/ acschemneuro.0c00122

18. Liu X, He L, Stensaas L, Dinger B, Fidone S (2009) Adaptation to chronic hypoxia involves immune cell invasion and increased expression of inflammatory cytokines in rat carotid body. Am J Physiol Lung Cell Mol Physiol 296:158-166. https://doi.org/10.1152/ajplung.90597.2008

19. Jacono FJ, Mayer CA, Hsieh Y-H, Wilson CG, Dick TE (2011) Lung and brainstem cytokine lev- els are associated with breathing pattern changes in a rodent model of acute lung injury. Respir Physiol Neurobiol 178:429-438. https://doi.org/ 10.1016/j.resp.2011.04.022

20. Petersen AMW, Pedersen BK (2005) The antiinflammatory effect of exercise. J Appl Physiol 98:1154-1162. https://doi.org/10.1152/japplphysiol.00164.2004

21. Pedersen BK, Akerstrom TCA, Nielsen AR, Fischer CP (2007) Role of myokines in exercise and metabolism. J Appl Physiol 103:1093-1098. https://doi.org/10.1152/japplphysiol.00080.2007

22. Janssen SPM, Gayan-Ramirez G, Van den Bergh A, Herijgers P, Maes K, Verbeken E, Decramer M (2005) Interleukin-6 causes myocardial failure and skeletal muscle atrophy in rats. Circulation 111:996-1005. https://doi.org/ 10.1161/01.CIR.0000156469.96135.0D

23. Hamilton C, Steinlechner B, Gruber E, Simon P, Wollenek G (2004) The oxygen dissociation curve: quantifying the shift. Perfusion 19:141144. https://doi.org/10.1191/0267659104pf734oa

24. Woyke S, Rauch S, Strohle M, Gatterer H (2021) Modulation of $\mathrm{Hb}-\mathrm{O} 2$ affinity to improve hypoxemia in COVID-19 patients. Clin Nutr 40:38-39. https://doi.org/10.1016/j.clnu.2020.04.036

25. Sainburg RL, Clark AL, Billman GE, Schlader ZJ, Mündel T, Milne K (2012) Hypoxia, focus hypobaric hypoxia. Encycl Exerc Med Heal Dis Springer Berlin Heidelberg 428-431. Epub ahead of print.

26. Verity R, Okell L, Dorigatti I. Winskill P, Whittaker C, Imai N, Cuomo-Dannenburg G, Thompson H, Walker P, Fu H, Dighe A, Griffin JT, Baguelin M, Bhatia S, Boonyasiri A, Cori A, Cucunubá Z, FitzJohn R, Gaythorpe K, Green W, Hamlet A, Hinsley W, Laydon D, Nedjati-Gilani G, Riley S, Elsland S, Volz E, Wang H, Wang Y, Xi X, A Donnelly C, Ghani AC, Ferguson NM (2020) Estimates of the severity of coronavirus disease 2019: a model-based analysis. Lancet Infect Dis 20:669-677. https://doi.org/10.1016/S1473-3099(20)30243-7

27. Kimura D, Totapally BR, Raszynski A, Ramachandran C, Torbati D (2008) The effects of CO2 on cytokine concentrations in endotoxin-stimulated human whole blood. Crit Care Med 36:2823-2827. https://doi.org/10.1097/CCM.0b013e318186f556

28. Liu W, Hualan L (2020) COVID-19: Attacks the 1-Beta chain of hemoglobin and captures the porphyrin to inhibit human heme metabolism. Chem Rxiv. Epub ahead of print. https://doi.org/ 10.26434/chemrxiv.11938173.v4

29. Komorowski M, Aberegg S (2020) Using applied lung physiology to understand COVID-19 patterns. Br J Anaesth 125:250-253. https://doi.org/ 
10.1016/j.bja.2020.05.019

30. Ottestad W, Hansen TA, Pradhan G, Stepanek J, Hoiseth LO, Kasin JL (2017) Acute hypoxia in a simulated high-altitude airdrop scenario due to oxygen system failure. J Appl Physiol 123:1443-1450. https://doi.org/10.1152/japplphysiol.00169.2017

31. Jia HP, Look DC, Shi L, Hickey M, Pewe L, Netland J, Farzan M, Wolford-Lenane C, Perlam S, Paul B, McCray Jr (2005) ACE2 receptor expression and severe acute respiratory syndrome coronavirus infection depend on differentiation of human airway epithelia. J Virol 79:14614-14621. https://
doi.org/10.1128/JVI.79.23.14614-14621.2005

32. Takagishi M, Waki H, Bhuiyan ME, Gouraud SS, Kohsaka A, Cui H, Yamazaki T, Paton JF, Maeda M, Takagishi M, Waki H, Bhuiyan ME, Gouraud SS, Kohsaka A, Cui H, Yamazaki T, Paton JF, Maeda M (2010) IL-6 microinjected in the nucleus tractus solitarii attenuates cardiac baroreceptor reflex function in rats. Am J Physiol Regul Integr Comp Physiol 298:183-190. https:// doi.org/10.1152/ajpregu.00176.2009

Translated by A. Polyanovsky 